[ORIGINAL ARTICLE

Volume 16 Issue 22021

DOI: 10.21315/aos2021.16.2.6

ARTICLE INFO

Submitted: $14 / 12 / 2020$

Accepted: 29/9/2021

Online: $22 / 12 / 2021$

\section{In Vitro Antimicrobial Activity and Aggregation Abilities of Probiotic Lactobacillus casei and Lactobacillus salivarius Against Oral Pathogens}

\author{
Darshyna Theena Thayalan ${ }^{\mathrm{a}}$, Rosmaliza Abdullah ${ }^{\mathrm{b}}$, Siti Suraiya \\ Md Noor ${ }^{b}$, Suharni Mohamad ${ }^{*}$
}
${ }^{a}$ School of Dental Sciences, Universiti Sains Malaysia, 16150 Kubang Kerian, Kelantan, Malaysia

${ }^{b}$ Department of Medical Microbiology and Parasitology, School of Medical Sciences, Universiti Sains Malaysia, 16150 Kubang Kerian, Kelantan, Malaysia

${ }^{\star}$ Corresponding author: suharni@usm.my

To cite this article: Thayalan DT, Abdullah R, Md Noor SS, Mohamad S (2021). In vitro antimicrobial activity and aggregation abilities of probiotic Lactobacillus casei and Lactobacillus salivarius against oral pathogens. Arch Orofac Sci, 16(2): 153-163. https://doi.org/10.21315/aos2021.16.2.6

To link to this article: https://doi.org/10.21315/aos2021.16.2.6

\begin{abstract}
The antagonistic effect of probiotics against oral pathogens merits exploration because these bacteria are beneficial to the host's health. The antimicrobial activity of two probiotic strains, Lactobacillus casei and Lactobacillus salivarius, as well as L. casei and L. salivarius combination (1:1), was investigated against Streptococcus mutans, Streptococcus sobrinus, Candida albicans, Candida glabrata and Candida tropicalis using agar-well diffusion, auto-aggregation and coaggregation assays. L. salivarius cell-free supernatant (CFS) alone exhibited greater inhibitory effect against Streptococci spp. compared to L. casei CFS alone and the combination. However, no inhibition was observed for Candida spp. L. salivarius alone exhibited significantly stronger auto-aggregation than $L$. casei alone $(p \leq 0.05)$ and $L$. casei and $L$. salivarius combination. L. salivarius exhibited strong coaggregation ability with Candida spp., followed by Streptococci spp. while L. casei exhibited coaggregation only with Streptococci spp. However, L. casei and L. salivarius combination did not display any coaggregation with all strains. $L$. salivarius alone exhibited a stronger antagonistic effect on the tested organisms than $L$. casei alone or in combination. Based on the results, both probiotic strains showed good antimicrobial activities against oral pathogens and should be further studied for their human health benefits.
\end{abstract}

Keywords: Agar diffusion; auto-aggregation; coaggregation; Lactobacillus spp.; oral pathogens

\section{INTRODUCTION}

Lactobacilli are lactic acid bacteria group which produce various antimicrobial substances that exhibit antagonistic activity against pathogenic organisms. Lactobacillus casei and Lactobacillus salivarius are among probiotic bacteria found in the gastrointestinal tract and oral cavity, respectively that exert therapeutic properties. Probiotics are described as "beneficial microorganisms which when administered in sufficient quantities, improve the microecological balance of the host and provide the host with a health benefit" (Hill et al., 2014). Several studies have indicated that 
probiotic bacteria could be used in the treatment and prevention of oral diseases such as periodontal diseases and dental caries (Wu et al., 2015; Jeong et al., 2018).

Probiotics are more effective in interacting with the host to maintain homeostasis, which traditional therapies cannot achieve (Allaker \& Stephen, 2017). They have great potential to inhibit pathogenic organisms through several mechanisms, such as $\mathrm{pH}$ alteration, antimicrobial compounds production, regulation of microbial pathogen growth through antagonism, compete for pathogen receptor binding sites, stimulate production of lactase by immune modulatory cells and suppress lowgrade inflammation (Monteagudo-Mera et al., 2019). In addition, probiotics acts as physical protective barrier by forming biofilm to protect against oral diseases. Probiotic bacterial adherence to oral tissues and enhance local immunity are another factor that promote the health of the host (Alok et al., 2017).

Many bacterial strains used as probiotics have the ability to aggregate and coaggregate, which plays an important role in the formation of biofilms to protect the host from pathogen colonisation. Aggregation ability is correlated with cell adherence properties. Some probiotic strains can inhibit the pathogens adherence to intestinal mucosa either by direct coaggregation with pathogens or by forming a barrier via auto-aggregation (Choi et al., 2018). Some probiotic lactobacilli species play important roles in microflora equilibrium and natural immunity in a variety of environments (Teanpaisan et al., 2011), and increase the concentration of excreted antimicrobial substances in the process of coaggregating (Kaewnopparat et al., 2013). The ability of bacterial strains to coaggregate is essential, as it can allow lactic acid bacteria strains to inhibit the growth of pathogenic strains in some ecological niches, such as the oral cavity. Lactobacillus probiotic bacteria present in yogurt have previously been shown to inhibit the growth and biofilm formation of Streptococcus mutans (Javid et al., 2015; Wu et al., 2019).

L. casei is a Gram-positive facultative heterofermentative bacteria, while L. salivarius is a Gram-positive obligately homofermentative bacteria. Lactobacillus species have been shown to have antimicrobial properties that can inhibit the growth of a variety of microbial pathogens (Jeong et al., 2018). Two strains of L. salivarius, K35 and K43, was demonstrated to inhibit the growth and expression of $S$. mutans virulence genes and reduced this pathogen's biofilm formation (Wu et al., 2015). L. casei ATCC 11578 influences the adherence of Streptococci to saliva-coated hydroxyapatite and release the already-bound Streptococci from hydroxyapatite (Stamatova \& Meurman, 2009).

While these studies yielded promising results, research on the effects of $L$. casei and L. salivarius, as well as their combinations, on oral pathogens is still limited. Most studies were primarily focused on the impact of probiotics on enteropathogens. By modifying the biofilm composition of the oral cavity, probiotics may be used as an alternative in preventing and treating oral infectious diseases (Jiang et al., 2016). Thus, this research was aimed to evaluate the antagonistic effects of $L$. case $i$ and L. salivarius against several oral pathogenic strains (S. mutans, S. sobrinus, C. albicans, C. glabrata and C. tropicalis). All microorganisms used in this study are the most common pathogens associated several oral diseases, i.e., dental caries and candidiasis. Mutans streptococci ( $S$. mutans and $S$. sobrinus) are considered to be major etiologic agents of dental caries, while Candida species are the most common causes of oral candidiasis (Pfaller et al., 2010). 


\section{MATERIALS AND METHODS}

An in-vitro experimental study was carried out at Medical Microbiology and Parasitology Laboratory, School of Medical Sciences, Universiti Sains Malaysia, Kelantan, Malaysia.

\section{Test Microorganisms}

Probiotic strains (L. casei ATCC 15883 and L. salivarius ATCC 11741), and oral pathogenic strains (S. mutans ATCC 25175, S. sobrinus ATCC 33478, Candida albicans HV27460, C. glabrata HV 27228 and C. tropicalis B27658) used in this study were commercially obtained from the American Type Cell Culture (ATCC, US).

\section{Lactobacillus Cell-Free Supernatant}

Preparation of $L$. casei and L. salivarius cell-free supernatant (CFS) was done as described by Coman et al. (2014). Each probiotic Lactobacillus strains was cultivated in De Man, Rogosa and Sharpe (MRS) broth (Oxoid, US) at $37^{\circ} \mathrm{C}$ for $24 \mathrm{~h}$. Crude CFS of Lactobacillus strains were collected by centrifugation at $12,000 \times \mathrm{g}$ for $20 \mathrm{~min}$ at $4{ }^{\circ} \mathrm{C}$ and sterilised by filtration using $0.2 \mu \mathrm{m}$ porous membranes. The final concentration of each Lactobacillus CFS was prepared to be $10^{8} \mathrm{CFU} / \mathrm{ml}$.

\section{Antimicrobial and Antifungal Activities}

In this study, antibacterial and antifungal activities of L. casei and L. salivarius and their combinations were evaluated using three different modified procedures: agarwell diffusion, auto-aggregation and coaggregation assays.

\section{Agar-Well Diffusion}

Agar-well diffusion test was done as described by Coman et al. (2014) with slight modifications of the tested probiotic where in this study, CFS of Lactobacillus strains was used instead of bacterial suspension. All pathogenic strains (S. mutans, S. sobrinus, C. albicans, C. glabrata and C. tropicalis) were lawn cultured over Brain-heart Infusion (BHI) agar (Oxoid, US). A $6 \mathrm{~mm}$ diameter wells were punched into agar plates and filled with $100 \mu \mathrm{l}\left(10^{8} \mathrm{CFU} / \mathrm{ml}\right)$ CFS of $L$. casei, L. salivarius, combination of L. casei + L. salivarius (1:1 ratio). Distilled water and $0.2 \%$ chlorhexidine gluconate were used as negative and positive controls, respectively. After incubation at $37^{\circ} \mathrm{C}$ for $48 \mathrm{~h}$, the diameters of zone of inhibition (in $\mathrm{mm}$ ) were measured using a digital calliper. This experiment was done in triplicates. The antimicrobial activity was recorded as growth-free inhibition zones measured from the edge of the wells.

\section{Auto-Aggregation and Coaggregation Assays}

Auto-aggregation refers to bacteria's selfbinding and self-recognition capacity, which can be seen macroscopically as bacterial clumps form at the bottom of culture tubes. Coaggregation, on the other hand, is the tendency of various bacterial strains to associate (Trunk et al., 2018). These abilities are critical for adherence to epithelial cells and the development of biofilms to protect the host from pathogens. In the present study, auto-aggregation and coaggregation assays were adapted from a previous study (Prabhurajeshwar \& Chandrakanth, 2017).

Briefly, L. casei and L. salivarius were cultivated in MRS broth at $37^{\circ} \mathrm{C}$ for $24 \mathrm{~h}$. After centrifugation at $6000 \times \mathrm{g}$ for $20 \mathrm{~min}$ at $4^{\circ} \mathrm{C}$, the pelleted cells were subsequently washed three times with sterile phosphate buffer solution (PBS) (pH 7.2). The cells were then resuspended in PBS to a final concentration of $10^{8} \mathrm{CFU} / \mathrm{ml}$. One hundred microlitre of Lactobacillus suspension and its combination (ratio of $1: 1 \mathrm{v} / \mathrm{v}$ ) were mixed by vortexing, followed by incubation at $37^{\circ} \mathrm{C}$ for $4 \mathrm{~h}$ without agitation. The absorbance, $\mathrm{A}_{600}$ was determined at $0 \mathrm{~h}\left(\mathrm{~A}_{0 \mathrm{hr}}\right)$ and $4 \mathrm{~h} \quad\left(\mathrm{~A}_{4 \mathrm{hr}}\right)$. This experiment was done in triplicates. The percentage of auto- 
aggregation was calculated using the following formula:

Auto-aggregation $=1-\left[\left(\mathrm{A}_{4 \mathrm{hr}} / \mathrm{A}_{0 \mathrm{hr}}\right)\right] \times 100 \%$

For the coaggregation assay, the suspension of Lactobacillus and oral pathogenic strains were prepared as described in the autoaggregation assay. The suspension of Lactobacillus strains and their combination were mixed with oral pathogen suspensions (ratio of $1: 1$ ). The mixture was then incubated at $37^{\circ} \mathrm{C}$ for $4 \mathrm{~h}$ without agitation. This experiment was done in triplicates. The absorbance was determined at $0 \mathrm{~h}$ and $4 \mathrm{~h}$ at $600 \mathrm{~nm}$. The coaggregation percentage was calculated using the following formula:

$$
\begin{aligned}
\text { Coaggregation }= & {\left[\left(\mathrm{A}_{\text {pathogen }}+\mathrm{A}_{\text {lactobacillus }}\right) / 2-\right.} \\
& \left.\mathrm{A}_{\text {mix }}\left(\mathrm{A}_{\text {pathogen }}+\mathrm{A}_{\text {lactobacillus }}\right) / 2\right] \\
& \times 100 \%
\end{aligned}
$$

where $A_{\text {pathogen }}$ and $A_{\text {lactobacillus represent }}$ the absorbances measured from of each strain, while $A_{\text {mix }}$ represents the absorbance measured from the mixture of the pathogen and Lactobacillus strains.

\section{Statistical Analysis}

All statistical analyses were performed using IBM SPSS Statistics 25 software (IBM Corp., NY). The data were assessed using ANOVA for agar-well diffusion test, Kruskal-Wallis test for auto-aggregation and
Mann-Whitney test for coaggregation. The significance level was set at $p<0.05$. The data were presented as mean \pm standard deviation (SD).

\section{RESULTS}

\section{Antimicrobial Activity of Lactobacillus CFS Using Agar-Well Diffusion}

Both Lactobacillus CFS demonstrated antimicrobial activity against $S$. mutans and $S$. salivarius, notable by the presence of inhibition halos around the wells (Fig. 1). L. salivarius alone exhibited better inhibition towards $S$. mutans and $S$. sobrinus compared to $L$. casei alone (Figs. $1 \mathrm{a}$ and $1 \mathrm{~b}$ ). However, no inhibition was observed for all Candida spp. (Figs. 1c-1e). The mean diameters of the inhibition zone exhibited by the Lactobacillus CFS on the tested pathogenic strains are presented in Table 1. When compared statistically among L. salivarius, L. casei and their combination, there is no significant difference $(p>0.05)$ between inhibition zones observed among both Streptococcus spp.

\section{Auto-Aggregation and Coaggregation Assays of Lactobacillus Spp.}

As shown in Fig. 2, L. salivarius alone exhibited the highest auto-aggregation

\begin{tabular}{|c|c|c|c|c|c|}
\hline \multirow{2}{*}{$\begin{array}{l}\text { Oral } \\
\text { pathogenic } \\
\text { strains }\end{array}$} & \multirow{2}{*}{$\begin{array}{c}\text { Positive control } \\
\text { (0.2\% Chlorhexidine } \\
\text { gluconate) }\end{array}$} & \multirow{2}{*}{$\begin{array}{c}\text { Negative } \\
\text { control } \\
\text { (distilled } \\
\text { water) }\end{array}$} & \multicolumn{3}{|c|}{ Mean diameter of inhibition ( $\mathrm{mm}$ ) } \\
\hline & & & L. salivarius & L. casei & $\begin{array}{l}\text { L. casei + } \\
\text { L. salivarius }\end{array}$ \\
\hline S. mutans & $31.33 \pm 0.83(+++)$ & - & $24.50 \pm 0.75(+++)^{*}$ & $12.50 \pm 1.53(++)^{*}$ & $22.50 \pm 0.40(+++)^{*}$ \\
\hline S. sobrinus & $24.17 \pm 0.90(+++)$ & - & $17.67 \pm 0.72(++)^{*}$ & $13.67 \pm 0.70(++)^{*}$ & $15.33 \pm 1.13(++)^{*}$ \\
\hline C. albicans & $20.67 \pm 1.42(+++)$ & - & - & - & - \\
\hline C. glabrata & $20.00 \pm 1.34(+++)$ & - & - & - & - \\
\hline C. tropicalis & $20.83 \pm 1.24(+++)$ & - & - & - & - \\
\hline
\end{tabular}
ability $(80.41 \% \pm 0.19)$, compared to $L$. casei

Table 1 Mean zone of inhibition probiotic L. casei, L. salivarius CFS using agar-well diffusion

Note: *One-way ANOVA test $(p>0.05)$

- no inhibition; + zone of inhibition less than $10 \mathrm{~mm}$ (low inhibition); ++ zone of inhibition 10-20 mm (intermediate inhibition);

+++ zone of inhibition more than $20 \mathrm{~mm}$ (strong inhibition) 

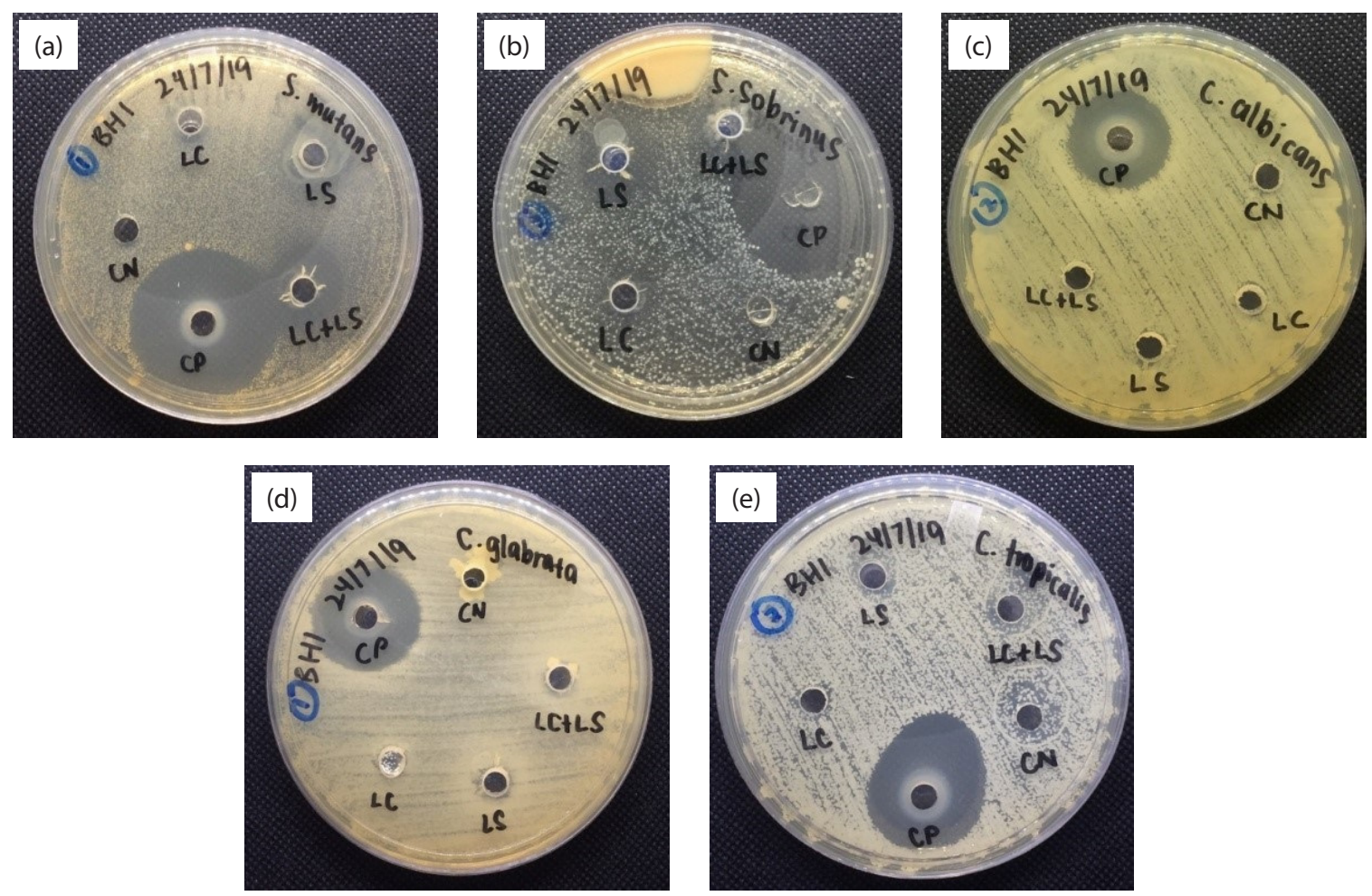

Fig. 1 Inhibitory effects of probiotics strains tested by agar-well diffusion method (a: S. mutans, b: S. sobrinus, c: C. albicans, d: C. glabrata, e: C. tropicalis, CP: 0.2\% chlorhexidine gluconate, CN: distilled water, LC: L. casei, LS: L. salivarius, LC+LS: L. casei + L. salivarius).

alone $(28.14 \% \pm 0.89)$ after $4 \mathrm{~h}$. However, combination of L. salivarius + L. casei exhibited lower auto-aggregation ability $(68.37 \% \pm 1.09)$ as compared to L. salivarius alone. Among the oral pathogenic strains, lower auto-aggregation ability was demonstrated by $S$. mutans $(9.62 \% \pm 1.22)$ and $S$. sobrinus $(6.71 \% \pm 0.68)$ as compared to the Candida spp. Among the Candida spp., C. tropicalis exhibited the highest auto-aggregation ability $(43.15 \% \pm 0.52)$. The percentage of auto-aggregation for all oral pathogenic strains ranged between $6 \%-43 \%$, which is a 2 -fold below the range of percentage of auto-aggregation for Lactobacillus strains and its combination $(28 \%-80 \%)$. There was a statistically significant difference in auto-aggregation potential between $L$. salivarius and $L$. casei alone (Kruskal-Wallis test, $p=0.027$ ). However, no significant different was observed among L. salivarius or L. casei alone and $L$. salivarius $+L$. casei combination $(p=0.539)$.
The coaggregation ability of Lactobacillus spp. with different oral pathogens is shown in Table 2. Among the tested strains, L. salivarius had similar coaggregation ability with both Streptococci spp. where the percentage of coaggregation against S. mutans was $26.55 \% \pm 1.08$ and against S. sobrinus was $21.00 \% \pm 0.73$. L. salivarius had a higher percentage of coaggregation ability against Streptococci spp. than L. casei. L. salivarius also exhibited slightly higher coaggregation ability against Candida spp. than against Streptococci spp. Among all the pathogenic strains, L. salivarius demonstrated the least coaggregation against $S$. sobrinus $(21.00 \% \pm 0.73)$ and the most coaggregation ability against $C$. tropicalis $(33.48 \% \pm 0.63)$. $L$. casei showed no coaggregation against all Candida spp. L. casei showed higher coaggregation ability against $S$. mutans $(17.32 \% \pm 0.35)$ than S. sobrinus $(14.28 \% \pm 0.75)$. However, the combination of both Lactobacillus spp. did not show any coaggregation with all tested oral pathogens. 
$X$ - Tested organism

Y- \% auto-aggregation

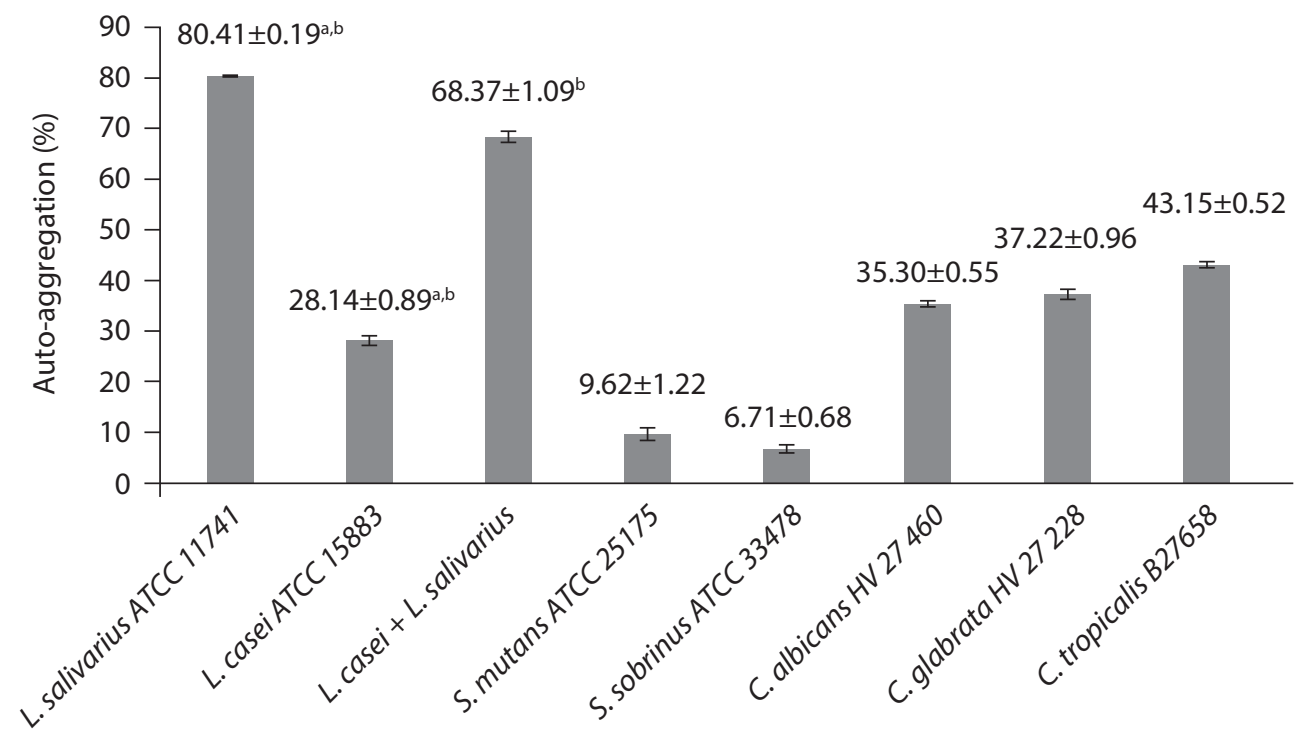

Fig. 2 Auto-aggregation of L. casei, L. salivarius and oral pathogenic strains. ${ }^{a}$ There was a statistically significant difference in auto-aggregation potential when comparing between $L$. salivarius and $L$. casei alone $\left(p \leq 0.05\right.$; Kruskal-Wallis test). ${ }^{b}$ No significant difference was observed between L. salivarius/L. casei alone and their combination (L. salivarius + L. casei) $(p \geq 0.05$; Kruskal-Wallis test).

Table 2 Coaggregation of L. casei and L. salivarius against oral pathogenic strains

\begin{tabular}{lccc} 
& \multicolumn{3}{c}{ Coaggregation (\%) } \\
\cline { 2 - 4 } Oral pathogenic strains & L. salivarius & L. casei & L. casei + L. salivarius \\
S. mutans & $26.55 \pm 1.08^{\mathrm{a}, \mathrm{b}}$ & $17.32 \pm 0.35^{\mathrm{a}}$ & - \\
S. sobrinus & $21.00 \pm 0.73^{\mathrm{a}, \mathrm{b}}$ & $14.28 \pm 0.75^{\mathrm{a}}$ & - \\
C. albicans & $28.13 \pm 1.02^{\mathrm{b}}$ & - & - \\
C. glabrata & $30.63 \pm 0.62^{\mathrm{b}}$ & - & - \\
C. tropicalis & $33.48 \pm 0.63^{\mathrm{b}}$ & - & - \\
\hline
\end{tabular}

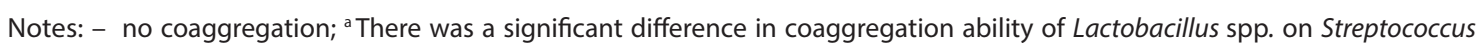
spp. (Mann-Whitney test; $p \leq 0.05$ ); ${ }^{\text {b }}$ No significant difference in the coaggregation ability of $L$. salivarius against oral pathogenic strains (Mann-Whitney test; $p>0.05$ ).

Statistically, there was a significant difference $(p=0.05)$ between coaggregation effects of L. salivarius and L. casei with Streptococci spp. However, no significant difference was observed in coaggregation ability of $L$. salivarius with all tested pathogenic strains $(p=0.499)$.

\section{DISCUSSION}

To date, the emergence of antibioticresistant bacteria has been a major source of concern for global health. As a result, probiotics with beneficial effects may be a feasible option for addressing this problem. Probiotics have been used as an adjunct to scaling and root planing, to improve clinical gingival bleeding and probing depths, as well as to minimise oral malodor in patients with 
chronic periodontitis and halitosis (Penala et al., 2016), implying their possible use in the treatment or prevention of oral diseases such as periodontal diseases and dental caries (Naghmouchi et al., 2020). Several previous studies reported that Lactobacillus spp. have an antimicrobial effect against various pathogens, but they primarily focused on enteropathogens (Prabhurajeshwar \& Chandrakanth, 2017; Tebyanian et al., 2017; Chen et al., 2019). The study on the effects of $L$. casei and L. salivarius, as well as their combinations, on oral pathogens are scarce. Thus, the present study was aimed to determine the antagonistic effect of these two probiotic strains and their combinations against selected oral pathogenic strains.

In this study, the probiotic L. casei and L. salivarius strains possess varying degrees of antibacterial and antifungal activities towards the oral pathogenic strains. The results of inhibitory activity vary between different methods used, revealing different antimicrobial mechanisms. In agar-well diffusion method, both Lactobacillus strains inhibited the growth of $S$. mutans and $S$. sobrinus. The finding was in line with other studies which reported the inhibition of S. mutans growth by L. salivarius (Wu et al., 2015; Krzyściak et al., 2017; Lin et al., 2017). However, in this study both CFS Lactobacillus strains and the combination did not exhibit any inhibition against Candida spp. In a previous study, Radi et al. (2015) demonstrated a low inhibition of Lactobacillus bacteria against Candida spp. However, in another study by Song \& Lee (2017) demonstrated strong antifungal activity of L. casei (ATCC 334) against blastoconidia and hyphal form of $C$. albicans, and inhibited Candida biofilm on the denture base resin. These variations could be due to different components presence in the bacterial suspension and CFS and different strains/ isolates used in the study.

The CFS contains several metabolites and amino acids with high antimicrobial and antioxidant activities, as determined by the GC-MS (Shehata et al., 2019). Previous studies reported that lactic acid and protein (bacteriocin) molecules in the CFS have antimicrobial properties (Hladíková et al., 2012; Alvarez-Sieiro et al., 2016). Lactic acid penetrates and disrupts the pathogen cell membrane due to its $\mathrm{pH}$ reduction and undissociated nature, resulting in the breakdown of the by-layers and transmembrane proton motive power force (Alakomi et al., 2000). The acidification of the membrane by lactic acid could have also enhanced the antimicrobial activities of other biomolecules such as diacetyl, which may require a low $\mathrm{pH}$ environment to function. Gram-positive bacteria possess a thick cell wall made up of teichuronic or teichoic acid polymers. These highly anionic lipid components that are exposed on the bacterial membrane structures are ideal targets for the cationic antimicrobial peptides (Omardien et al., 2016). Bacteriocins, on the other hand, are closely cationic active compounds that easily interact with anionic lipid components of the membrane, resulting in the creation of pores that facilitate cell lysis (Oscáriz \& Pisabarro, 2001). This mechanism could explain why bacterial species with higher anionic lipid content are more susceptible to the antibacterial effect exhibited by these cationic active compounds.

The combination of both Lactobacillus CFS demonstrated antagonistic affect and greater inhibition against $S$. mutans than L. casei alone, but less inhibition compared to $L$. salivarius alone. Antagonism is thought to be one of the mechanisms for the action of probiotic bacteria. This antipathogenic activity involves competitive exclusion and the production of antimicrobial compounds. In addition, the antagonistic effect of probiotics against oral pathogens may also be attributed to different mechanisms of action, such as biosurfactant production, adhesion and coaggregation (Monteagudo-Mera et al., 2019).

The auto-aggregation and coaggregation abilities of Lactobacillus spp. and the oral pathogenic strains were investigated in this study because adhesion ability is an 
essential property of the probiotics to undergo transient colonisation. This helps to facilitate immunomodulatory effects and prevents the adherence of pathogens to epithelial receptors (MonteagudoMera et al., 2019). In the present study, Lactobacillus probiotic strains exhibited twice a range of percentage of auto-aggregation compared to oral pathogenic strains. This result was consistent with a previous study (Prabhurajeshwar \& Chandrakanth, 2017), which found that probiotic strains had a 2.5fold auto-aggregation capacity as compared to oral pathogenic strains. Lactobacilli with high autoaggregation ability showed high hydrophobicity (Chen et al., 2010; Nikolic et al., 2010), and as a result better adherence to the cells. Auto-aggregation is one of the first steps in the formation of biofilm and can result in the formation of microcolonies. The cells can self-recognise and bind to the substrate by expressing surface adhesins (Trunk et al., 2018).

Coaggregation of probiotic microorganisms with pathogens is essential in creating an unfavourable environment for oral pathogens, inhibiting pathogen overgrowth and proliferation, reducing pathogen growth and facilitating pathogen removal. Biofilm formation helps the pathogens to become more resistant to the host defence mechanism and antimicrobial compounds, thus the coaggregation of probiotic strains with pathogens creates a barrier that prevents biofilm formation (Matsubara et al., 2016). In this study, L. salivarius could coaggregate with S.mutans, S. sobrinus, C. albicans, C. glabrata and C.tropicalis, while L. casei could only coaggregate with $S$. mutans and $S$ sobrinus. Probiotic bacteria interact closely with pathogens during this process, allowing them to release anti-pathogenic substances in close proximity to the pathogens. However, the combination of $L$. casei and $L$. salivarius did not work synergistically against oral pathogens in this study as no coaggregation was observed with S. mutans, S. sobrinus, C. albicans, C. glabrata and C. tropicalis.
The use of only a single time point (i.e., $4 \mathrm{~h}$ ) in the aggregation assays in the present study could be a limitation of this study. More research should be done at various time points and stages of microbial growth to see whether there is a difference in the effect of aggregation abilities.

\section{CONCLUSION}

L. salivarius CFS alone demonstrated greater antimicrobial activity than $L$. casei alone or in combination. L. salivarius showed superior auto-aggregation and coaggregation abilities on its own. The combination of $L$. salivarius and L. casei did not work synergistically against selected oral pathogens because L. salivarius alone has a stronger antagonistic effect than the combination. To the best of our knowledge, this is the first study to report the antagonistic effect of $L$. salivarius and L. casei combination on selected oral pathogens. The association between L. salivarius adhesion, aggregation and cell surface properties should be investigated further to determine its possible probiotic use.

\section{ACKNOWLEDGEMENTS}

We thank Dr. Mohamad Arif Awang Nawi from School of Dental Sciences, Universiti Sains Malaysia (USM) for his help in the statistical analysis. We also thank the staff of Medical Microbiology and Parasitology Laboratory, School of Medical Sciences, USM and Craniofacial Science Laboratory, School of Dental Sciences, USM who were involved in this study. 


\section{REFERENCES}

Alakomi HL, Skyttä E, Saarela M, MattilaSandholm T, Latva-Kala K, Helander IM (2000). Lactic acid permeabilizes gramnegative bacteria by disrupting the outer membrane. Appl Environ Microbiol, 66(5): 2001-2005. https://doi.org/10.1128/AEM .66.5.2001-2005.2000

Allaker RP, Stephen AS (2017). Use of probiotics and oral health. Curr Rural Health Rep, 4(4): 309-318. https://doi.org/10.1007/ s40496-017-0159-6

Alok A, Singh ID, Singh S, Kishore M, Jha PC, Iqubal MA (2017). Probiotics: A new era of biotherapy. Adv Biomed Res, 6: 31. https://doi.org/10.4103/2277-9175.192625

Alvarez-Sieiro P, Montalbán-López M, Mu D, Kuipers OP (2016). Bacteriocins of lactic acid bacteria: Extending the family. Appl Microbiol Biotechnol, 100(7): 2939-2951. https://doi.org/10.1007/s00253-016-7343-9

Chen X, Tian F, Liu X, Zhao J, Zhang HP, Zhang $\mathrm{H}$ et al. (2010). In vitro screening of lactobacilli with antagonistic activity against Helicobacter pylori from traditionally fermented foods. F Dairy Sci, 93(12): 56275634. https://doi.org/10.3168/jds.2010 $-3449$

Chen CC, Lai CC, Huang HL, Huang WY, Toh HS, Weng TC et al. (2019). Antimicrobial activity of Lactobacillus species against carbapenem-resistant enterobacteriaceae. Front Microbiol, 10: 789. https://doi.org/10 $.3389 /$ fmicb.2019.00789

Choi AR, Patra JK, Kim WJ, Kang SS (2018). Antagonistic activities and probiotic potential of lactic acid bacteria derived from a plant-based fermented food. Front Microbiol, 9: 1963. https://doi.org/10 $.3389 /$ fmicb.2018.01963
Coman MM, Verdenelli MC, Cecchini C, Silvi S, Orpianesi C, Boyko $\mathrm{N}$ et al. (2014). In vitro evaluation of antimicrobial activity of Lactobacillus rhamnosus IMC $501^{\circledR}$, Lactobacillus paracasei IMC $502^{\circledR}$ and SYNBIO $^{\circledR}$ against pathogens. $\mathcal{f} A p p l$ Microbiol, 117(2): 518-527. https://doi.org/ $10.1111 /$ jam. 12544

Hill C, Guarner F, Reid G, Gibson GR, Merenstein DJ, Pot B et al. (2014). Expert consensus document. The International Scientific Association for Probiotics and Prebiotics consensus statement on the scope and appropriate use of the term probiotic. Nat Rev Gastroenterol Hepatol, 11(8): 506-514. https://doi.org/10.1038/ nrgastro.2014.66

Hladíková Z, Smetanková J, Greif G, Greifová M (2012). Antimicrobial activity of selected lactic acid cocci and production of organic acids. Acta Chim Slov, 5(1): 80-85. https://doi.org/10.2478/v10188-012-0013-3

Javid AZ, Amerian E, Basir L, Ekrami A, Haghighi-zadeh MH (2015). Effects of short-term consumption of probiotic yogurt on Streptococcus mutans and lactobacilli levels in 18-30 years old students with initial stages of dental caries in Ahvaz City. Nutr Food Sc Res, 2(2): 7-12.

Jeong D, Kim DH, Song KY, Seo KH (2018). Antimicrobial and anti-biofilm activities of Lactobacillus kefiranofaciens DD2 against oral pathogens. F Oral Microbiol, 10(1): 1472985. https://doi.org/10.1080/ 20002297.2018.1472985

Jiang Q, Stamatova I, Kainulainen V, Korpela R, Meurman JH (2016). Interactions between Lactobacillus rhamnosus GG and oral micro-organisms in an in vitro biofilm model. BMC Microbiol, 16: 149. https://doi.org/10.1186/s12866-016-0759-7 
Kaewnopparat S, Dangmanee N, Kaewnopparat $\mathrm{N}$, Srichana T, Chulasiri M, Settharaksa $S$ (2013). In vitro probiotic properties of Lactobacillus fermentum SK5 isolated from vagina of a healthy woman. Anaerobe, 22: 6-13. https://doi.org/10.1016/j.anaerobe .2013 .04 .009

Krzyściak W, Kościelniak D, Papież M, Vyhouskaya P, Zagórska-Świeży K, Kołodziej I et al. (2017). Effect of a Lactobacillus salivarius probiotic on a double-species Streptococcus mutans and Candida albicans caries biofilm. Nutrients, 9(11): 1242. https://doi.org/10.3390/ nu9111242

Lin X, Chen X, Tu Y, Wang S, Chen H (2017). Effect of probiotic lactobacilli on the growth of Streptococcus mutans and multispecies biofilms isolated from children with active caries. Med Sci Monit, 23: 4175-4181. https://doi.org/10.12659/ msm. 902237

Matsubara VH, Wang Y, Bandara HMHN, Mayer MPA, Samaranayake LP (2016). Probiotic lactobacilli inhibit early stages of Candida albicans biofilm development by reducing their growth, cell adhesion, and filamentation. Appl Microbiol Biotechnol, 100(14): 6415-6426. https://doi.org/10 $.1007 / \mathrm{s} 00253-016-7527-3$

Monteagudo-Mera A, Rastall RA, Gibson GR, Charalampopoulos D, Chatzifragkou A (2019). Adhesion mechanisms mediated by probiotics and prebiotics and their potential impact on human health. Appl Microbiol Biotechnol, 103(16): 64636472. https://doi.org/10.1007/s00253-019 $-09978-7$

Naghmouchi K, Belguesmia Y, Bendali F, Spano G, Seal B, Drider D (2020). Lactobacillus fermentum: A bacterial species with potential for food preservation and biomedical applications. Crit Rev Food Sci Nutr, 60(20): 3387-3399. https://doi.org/ $10.1080 / 10408398.2019 .1688250$
Nikolic M, Jovcic B, Kojic M, Topisirovic L (2010). Surface properties of Lactobacillus and Leuconostoc isolates from homemade cheeses showing auto-aggregation ability. Eur Food Res Technol, 231: 925-931. https://doi.org/10.1007/s00217-010-1344-1

Omardien S, Brul S, Zaat SAJ (2016). Antimicrobial activity of cationic antimicrobial peptides against grampositives: Current progress made in understanding the mode of action and the response of bacteria. Front Cell Dev Biol, 4: 111. https://doi.org/10.3389/fcell .2016 .00111

Oscáriz JC, Pisabarro AG (2001). Classification and mode of action of membrane-active bacteriocins produced by gram-positive bacteria. Int Microbiol, 4(1): 13-19. https://doi.org/10.1007/s101230100003

Penala S, Kalakonda B, Pathakota KR, Jayakumar A, Koppolu P, Lakshmi BV et al. (2016). Efficacy of local use of probiotics as an adjunct to scaling and root planing in chronic periodontitis and halitosis: A randomized controlled trial. F Res Pharm Pract, 5(2): 86-93. https://doi.org/10.4103/2279-042X.179568

Pfaller MA, Diekema DJ, Gibbs DL, Newell VA, Ellis D, Tullio V et al. (2010). Results from the ARTEMIS DISK Global Antifungal Surveillance Study, 1997 to 2007: A 10.5year analysis of susceptibilities of Candida Species to fluconazole and voriconazole as determined by CLSI standardized disk diffusion. I Clin Microbiol, 48(4): 13661377. https://doi.org/10.1128/JCM.02117 $-09$

Prabhurajeshwar C, Chandrakanth RK (2017). Probiotic potential of Lactobacilli with antagonistic activity against pathogenic strains: An in vitro validation for the production of inhibitory substances. Biomed F, 40(5): 270-283. https://doi.org/ 10.1016/j.bj.2017.06.008 
Radi NAM, Abdelmonem AA, Ziada AA (2015). A study on the antifungal effects of Lactobacillus spp. on Candida. Al-Azhar Assiut Med F, 13(Suppl 1), 122-125.

Shehata MG, Badr AN, El Sohaimy SA, Asker D, Awad TS (2019). Characterization of antifungal metabolites produced by novel lactic acid bacterium and their potential application as food biopreservatives. Ann Agric Sci, 64(1): 71-78. https://doi.org/10 $.1016 /$ j.aoas.2019.05.002

Song YG, Lee SH (2017). Inhibitory effects of Lactobacillus rhamnosus and Lactobacillus casei on Candida biofilm of denture surface. Arch Oral Biol, 76: 1-6. https://doi .org/10.1016/j.archoralbio.2016.12.014

Stamatova I, Meurman HJ (2009). Probiotics: Health benefits in the mouth. Am $\mathcal{F}$ Dent, 22(6): 329-338.

Teanpaisan R, Piwat S, Dahlén G (2011). Inhibitory effect of oral Lactobacillus against oral pathogens. Lett Appl Microbiol, 53(4): 452-459. https://doi.org/10.1111/j .1472-765X.2011.03132.x
Tebyanian H, Bakhtiari A, Karami A, Kariminik A (2017). Antimicrobial activity of some Lactobacillus species against intestinal pathogenic bacteria. Int Lett Nat Sci, 65: 10-15. https://doi.org/10.18052/www. scipress.com/ILNS.65.10

Trunk T, Khalil HS, Leo JC (2018). Bacterial autoaggregation. AIMS Microbiol, 4(1): 140-164. https://doi.org/10.3934/microbiol .2018 .1 .140

Wu CC, Lin CT, Wu CY, Peng WS, Lee MJ, Tsai YC (2015). Inhibitory effect of Lactobacillus salivarius on Streptococcus mutans biofilm formation. Mol Oral Microbiol, 30(1): 16-26. https://doi.org/10 $.1111 /$ omi. 12063

Wu CY, He SJ, Mar K, Hsu CYS, Hung SL (2019). Inhibition of Streptococcus mutans by a commercial yogurt drink. I Dent Sci, 14(2): 198-205. https://doi.org/10.1016/ j.jds.2018.11.007 